\title{
A New Framework of Software Testing Using Cloud Computing for Banking Applications
}

\author{
Aya M. El Nagdy ${ }^{*}$, Mostafa Abd El Azim² ${ }^{2}$, Ashraf AbdelRaouf ${ }^{1,2}$ \\ ${ }^{1}$ Computer Science Department, Arab Academy for Science, Technology \& Maritime Transport, Cairo, Egypt. \\ 2 Faculty of Computer Science, Misr International University, Cairo, Egypt. \\ * Corresponding author. Email: aya.elnagdy@gmail.com \\ Manuscript submitted November 1, 2016; accepted May 20, 2017. \\ doi: 10.17706/jsw.12.8.657-663
}

\begin{abstract}
In Recent years, Cloud Computing has considered as a potential technology in software industry as a resource base. Cloud Computing provides many advantages for organizations and companies to increase their profit in many fields and perspectives. One of these fields is Software Testing. In Software Development Life Cycle (SDLC), software testing is considered as an essential activity that requires a lot of time and high resources expenses to be deployed in efficient way. Cloud computing can help to provide test environments, resources, software licenses, tools and infrastructure at an affordable budget without the need to build another on-premises infrastructure for testing purpose.

This paper presents a new approach for using cloud computing testing methodology and an implementation of this approach to enhance the software testing process in Banking Industry. The paper proofs that cloud computing approach can reduce the operating and labour cost by $40-60 \%$ and decrease the required time by $30 \%$. Saving time will minimize the effort needed to implement testing environment.
\end{abstract}

Key words: Cloud testing, software testing, software testing as a service, testing banking applications.

\section{Introduction}

Software testing is not a single activity but a series of tasks and steps that need to be executed along with the software development life cycle activity [1]. Software testing ensure that the product is delivered with no bugs and errors. Software testing is expensive activity that require $40 \%-60 \%$ of software development cost. By time software testing became more important due to the increasing of technological complexities, software sourcing challenges, and high business applications requirements. These complexities make the simulation of testing environment using on-premises facilities similar to production environment unaffordable. As it can typically take weeks or months to set up a simple test environment for a single application. This is why most banking institutions reduce, ignore or refuse to execute the complete cycle of software testing process [2].

A core banking system is the software application used to support most common banking transactions. Core banking functions differ depending on the type of bank. Core banking systems are often specialized for a particular type of banking. Products that are designed to deal with many types of core banking functions are referred to as universal banking systems. Banking system is a group or network of institutions that provide financial services. Banking sector is described as critical and risk adverse conservative environment. Banking domain is focused on studying all the factors which have great impact on risk like accounts, assets and investments of their clients. Software testing is also about reporting and risk analysis 
of all bugs and issues in software application while testing [3]. This has led to indirect relationship between Banking sector and Software testing process.

Using On premise infrastructure make the simulation of testing environment similar to production environment is unaffordable. Which encourage banking domain to refuse executing the complete cycle of software testing process. In 2013, many banks affected by a variety of software faults in production environment [4]. The core of this issue that banking applications are so complex and need many tests to be run to be quite sure that there are no bugs in software applications.

Cloud Computing open a lot of opportunities and alternatives to enhance the testing process. These enchantments such as fast scalability, reduce the time, cost and effort spend in traditional testing process. The simulation of test environment become easier as cloud computing paradigm enable access to in-demand high available of scalable services and resources with unlimited storage.

The remainder of this paper is organized as follows; in Section 2, there is a short background on cloud computing and software testing using cloud computing; in Section 3 we describe our research methodology; in Section IV we present an evaluation of review results and identify gaps as well as opportunities; and we conclude the paper in Section 4.

\section{Cloud Computing}

Cloud Computing is a computing model, which has a great influence on a lot of research fields. One of these fields is software testing process. Cloud Computing reduces the execution time of testing process with minimum efforts, low budget with unlimited storage, availability of scalable servers and resources [5].

\subsection{Characteristics of Cloud Computing}

Rapid elasticity allows end users easily and rapidly provision new services and release them, enabling them to pay for what they utilize and how much they use it. On-demand self-service is an appealing characteristic for consumers because a cloud computing provider pools its computing resources in order to serve multiple consumers by means of a multi-tenant provisioning model.

\subsection{Virtualization and Testing}

Software testing is an important activity of the software development life cycle (SDLC), challenges in software testing is building and maintaining a real-world test environment at the project similar to production environment. Virtualization technology has been utilized in testing various software since 1960 [6]. The concept that affect software testing as online service are domain knowledge, infrastructure, security, pricing, communication and skills. Online testing reduces cost related to building and maintaining testing environment.

\subsection{Testing Process and the Cloud}

There are several factors to be considered during testing in the cloud:

- Testing is a periodic activity and requires new environments to be set up for each project similar to production environment.

- Testing is considered an important but not a business-critical activity. Moving testing to the cloud computing is seen as a safe environment because it doesn't include sensitive corporate and individual data and has minimal impact on the organization's business activities.

- Applications become dynamic, distributed and component-based and complex [7].

\subsection{What Is Cloud Testing?}

Cloud Testing is common between software testing and cloud computing in which simulated, real-world 
web traffic is used to test cloud-based web applications. It simulates real world user traffic by using the term of load and stress testing web sites. The ability and costs to simulate Web traffic for software testing purposes has been an inhibitor to overall Web reliability. Cloud testing aligns with concept of cloud and software as a service (SaaS) [8]. Cloud testing also verifies and validates specific cloud functions, including redundancy and performance scalability.

\subsection{Why Cloud Testing Is Important?}

Cloud based test automation tools bring several benefits over and above those normally delivered by traditional test automation tools. Here are top three benefits:

Cost effective: Total Cost of Ownership in cloud based automation tools is less than traditional testing process. Cloud computing helps to provide test environments, resources, software licenses, tools and infrastructure at an affordable budget without the need to purchase them. It provides pay-per-use services.

Benefits of Virtualization: Virtualization brings the benefit of resource sharing with reduced capital costs.

More collaboration: Cloud based automation tools make it possible for teams spread across different locations and sites to easily collaborate with each other [9].

\section{Proposed Framework}

With the rise of existing and non-traditional competition between banks to satisfy the customers need which become so complex and hard. The need to implement cloud computing technology has increased to provide services and sharing of resources with less time and cost. So, this paper builds an empirical comparison between implementing testing environment for banking system on cloud computing and on premises infrastructure to get the advantages and disadvantages of each implementation method. In Fig. 1, it shows the framework of implementation phases of building testing environment on cloud computing.

Our testing environment which is installed on both platforms include the installation of IBM Rational Applications. Rational tools provide a set of capabilities delivered as a part of a collaborative and integrated range of products [10]. One of these products is rational team concert (RTC) which enhance the team collaboration with integrated features included work items, build and software configuration management. Rational Performance tester (RPT) application is deployed to test the performance of RTC. When the bank builds its testing environment on cloud computing, there is a data security challenges must be addressed [11].

Data Security is the security and confidentiality of financial and clients' personal data is paramount and restricted. Banks cannot afford the risk of security breach. So, we designed our test case to be quite sure that no confidential or security data will be required from banking system.

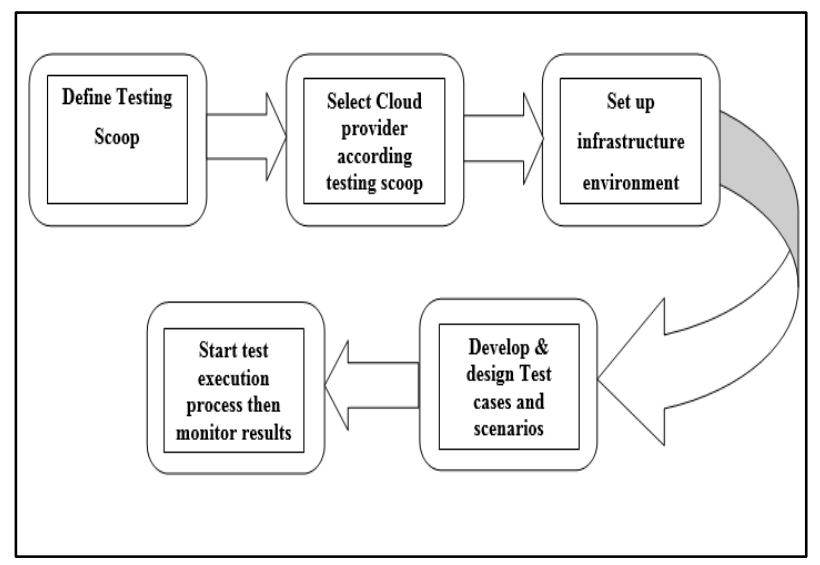

Fig. 1. Proposed framework. 


\subsection{Building Testing Environment on Virtual Machines (On Premises)}

Our testing environment was built totally on a virtual machine as a comparison study with that built on cloud computing platform. As shown in Table 1, which include all the required steps to build our test environment for banking system in virtual machines. It includes the cost and time for every single task. The cost of purchasing IBM rational tools are not added to this compression because it will be the same in both environments. The setup of Virtual machine is divided into three main phases:

1) Installing and configuring the licenses of operating system then configuration the network connection and installing Firefox browser for testing purpose.

2) Start with uploading IBM tools on virtual machines then start to install rational team concert and rational performance tester applications after that the configuration steps which include configure licenses, rational licenses key server for rational tools and create database and application server. Finally create 40 users with different roles in RTC and create project with workspace in RPT.

3) Recording the performance load test case for RTC application using RPT, after that run this test script and save the results.

Table 1. Detailed Steps to Build Test Environment on Cloud Computing and on Premise Infrastructure

\begin{tabular}{|c|c|c|c|c|c|}
\hline \multicolumn{3}{|l|}{ On Premise infrastructure } & \multicolumn{3}{|l|}{ Cloud Computing } \\
\hline Steps & Cost & Time & Steps & Cost & Time \\
\hline $\begin{array}{l}\text { 1) Install workstation player } 10 \text { for OS } \\
64 \text { bit }\end{array}$ & $250 \$$ & 10 hours & $\begin{array}{l}\text { 1) Determine the } \mathrm{S} / \mathrm{W} \text { and } \mathrm{H} / \mathrm{W} \\
\text { requirement for RTC and RPT }\end{array}$ & $\mathrm{N} / \mathrm{A}$ & 2 hours \\
\hline $\begin{array}{l}\text { 2) Install OS window server } 2008 \text { r2 "64 } \\
\text { bit" }\end{array}$ & $560 \$$ & 10 hours & $\begin{array}{l}\text { 2) Select the cloud provider that } \\
\text { provides these requirements with } \\
\text { good price }\end{array}$ & $220-250 \$$ & 3 hours \\
\hline 3) Configure OS licenses & $\mathrm{N} / \mathrm{A}$ & 4 hours & $\begin{array}{l}\text { 3) check the network configuration } \\
\text { on VM }\end{array}$ & N/A & 1 hours \\
\hline 4) Configure VM network & $\mathrm{N} / \mathrm{A}$ & 3hours & 4) Install Firefox browser & Free trail & 2 hours \\
\hline 5) Install Firefox browser & $\begin{array}{l}\text { Free } \\
\text { trail }\end{array}$ & 2hours & 5) Upload IBM rational applications & N/A & 6 hours \\
\hline 6) Upload IBM rational tools & $\mathrm{N} / \mathrm{A}$ & 4hours & 6) Set up Application server & N/A & 4 hours \\
\hline 7) Set up Application server & $\mathrm{N} / \mathrm{A}$ & 4 hours & 7) Set up database server & $\mathrm{N} / \mathrm{A}$ & 4 hours \\
\hline 8) Set up database server & $\mathrm{N} / \mathrm{A}$ & 4 hours & $\begin{array}{l}\text { 8) Install and configure (RTC) } \\
\text { application }\end{array}$ & N/A & 5 hours \\
\hline $\begin{array}{l}\text { 9) Install and configure (RTC) } \\
\text { application }\end{array}$ & $\mathrm{N} / \mathrm{A}$ & 5 hours & $\begin{array}{l}\text { 9) Configure RLKS For rational } \\
\text { applications }\end{array}$ & N/A & 5 hours \\
\hline $\begin{array}{l}\text { 10) Configure RLKS for rational } \\
\text { applications }\end{array}$ & $\mathrm{N} / \mathrm{A}$ & 5 hours & $\begin{array}{l}\text { 10) Create database connections for } \\
\text { RTC }\end{array}$ & N/A & 4 hours \\
\hline 11) Create database connections for RTC & $\mathrm{N} / \mathrm{A}$ & 2 hours & $\begin{array}{l}\text { 11) Create projects and users with } \\
\text { different roles }\end{array}$ & $\mathrm{N} / \mathrm{A}$ & 2 hours \\
\hline $\begin{array}{l}\text { 12) Create projects and users with } \\
\text { different roles }\end{array}$ & $\mathrm{N} / \mathrm{A}$ & 16 hours & $\begin{array}{l}\text { 12) Install Rational performance tester } \\
\text { application }\end{array}$ & $\mathrm{N} / \mathrm{A}$ & 16 hours \\
\hline $\begin{array}{l}\text { 13) Install Rational performance tester } \\
\text { application }\end{array}$ & $\mathrm{N} / \mathrm{A}$ & 10 hours & $\begin{array}{l}\text { 13) Configure workspace and create } \\
\text { projects }\end{array}$ & N/A & 10 hours \\
\hline $\begin{array}{l}\text { 14) Configure workspace and create } \\
\text { projects }\end{array}$ & $\mathrm{N} / \mathrm{A}$ & 32 hours & $\begin{array}{l}\text { 14) Record RTC performance HTTP } \\
\text { test }\end{array}$ & N/A & 32 hours \\
\hline 15) Record RTC performance HTTP test & N/A & 3 hours & 15) Run test case and save results & N/A & 3 hours \\
\hline 16) Run test case and save results & $\mathrm{N} / \mathrm{A}$ & 3 hours & & $\mathrm{N} / \mathrm{A}$ & 3 hours \\
\hline Total & $810 \$$ & $\begin{array}{c}117 \\
\text { hours }\end{array}$ & Total & $250 \$$ & 102 urs \\
\hline
\end{tabular}

\subsection{Building Testing Environment on Cloud Computing}


Our testing environment was built totally on a cloud environment with configuration similar to that built on virtual machine (as explained above). As shown in Table I, which include all the required steps to build our test environment for banking system in cloud computing. It includes the cost and time for every single task. Building the cloud environment have some similar steps as in virtual machine. The setup of cloud computing is divided into three main phases:

1) Determining the S/W and H/D requirements for installing RTC and RPT on cloud computing. Then selecting the cloud provider that can offer these requirements with reasonable prices. In this research, we choose Google as cloud provider as it provides all the required hardware and software capabilities with fast response and affordable price.

2) It is time to check all the required S/W and H/D capabilities are configured correctly in this VM on cloud computing including Network setup. Network`s check is about checking remote access protocol (RAP) that used by cloud provider for client-to-server session communication.

3) Applying all the same steps (from step 4 till step 15 as explained in Table I) as in the previously mentioned case in virtual machine environment setup.

\section{Results}

As Table 1, shows that there is great difference in the total time and cost required to build testing environment for banking industry in both cloud computing and on premises infrastructure methods.

Building testing environment in cloud infrastructure requires 102 hours and $250 \$$ but for on premises infrastructure requires 117 hours and $810 \$$. This represent cost reduction with $40-60 \%$ and time reduction almost with $30 \%$.

This is proof that our objective regarding cloud computing is the best choice to build testing environment. Using cloud computing decrease the time and cost spend in building test environment. Fig. 2 , shows that the total cost of using on premises infrastructure and cloud computing environment over 5 years. It explains the big increasing difference in cost between the two types of infrastructure.

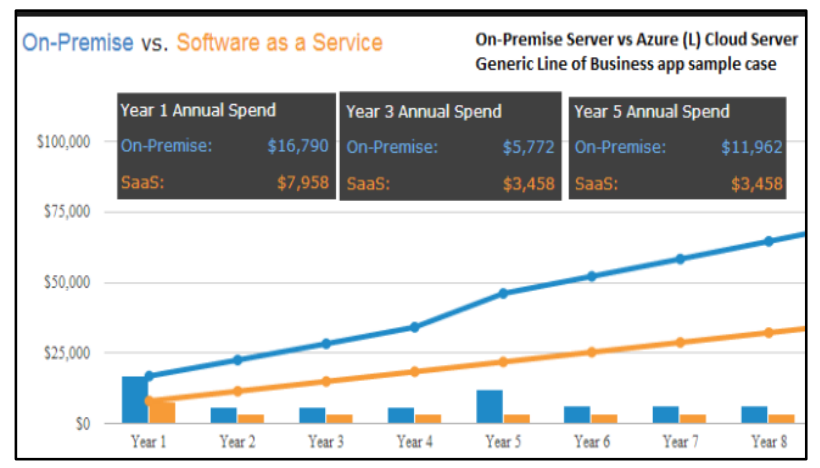

Fig. 2. On Premise vs cloud computing [12].

The annual expenses of cloud computing will be almost the same along the 5 years. But for on premises server the annual expenses will be increased after 3 years for maintenance purpose and after 5 years the cost will be increased again for renewing these infrastructure servers. Fig. 2, Show the annual expenses of cloud computing and on premises server contacted on bar chart with two colours, Blue one represent the on premises servers and orange one shows the cloud computing. Cost and time over 8 years are the main two axes of this bar chart. On the other hand, we developed a load test script that measure the performance of RTC application using RPT. This script is used to measure the required time to create 40 users on RTC application. The performance report is extracted after running the load test script on both environments as 
shown in Fig. 3 (a) and Fig. 3 (b).

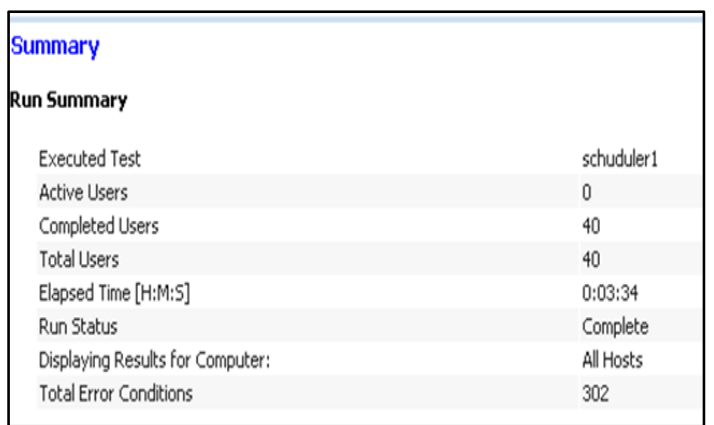

Fig. 3. (a) Performance on cloud environment

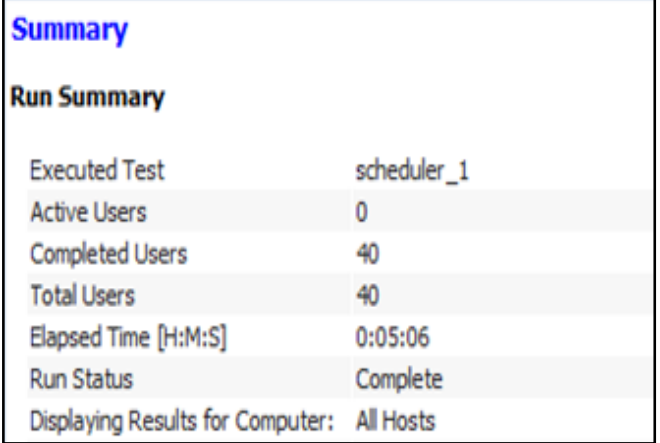

Fig. 3. (b) Performance on virtual servers

Fig. 3-a and 3-b, show the performance report for running load test script for RTC application on both environments. This explains that running load test script on cloud computing has extremely better performance against that of on premise infrastructure. As creating 40 users on cloud computing takes 3:34 minutes (214 seconds) only but on virtual machines takes 5:06 minutes (306 seconds) which represent time reduction with $30 \%$. This help to reduce the required time and minimize the effort spend in user acceptance testing phase.

\section{Conclusion and Future Work}

The general objective of this research is to develop cloud computing user acceptance test framework for banking industry. Accordingly, to achieve this objective. The comparison between implementing a test environment for banking industry on premises infrastructure and cloud computing are done. It is concluded from this comparison that cloud computing method will save the operating and labour cost by $40-60 \%$ and decrease the needed time by $30 \%$. Also, cloud testing can get over the challenges of traditional testing process like missing deadline and test reuse.

For future work, it is recommended to implement the production live environment for banking industry on cloud environment. When a bank moves into cloud computing, there are two primary challenges that must to be addressed: security and regulatory compliance. So, it is also recommended to build this environment using hybrid deployment method. Banks would use hybrid cloud for highly secure transactions and use a public cloud of upper layer of its applications. Regulatory standard organizations should conduct more research and should update security guidelines [12].

\section{References}

[1] Rohit, K., \& Sarbjeet, S. (November 2014). Cloud testing: Perspective and challenges. International Journal of Computer Applications, 106(17).

[2] Vanitha, K., A. \& Alagarsamy, K., (Spetember 2012). Conventional software testing vs. cloud testing. International Journal of Scientific \& Engineering Research.

[3] Sharon, R. (July 2008). Agile Testing and the Banking/Finance Domain...Should We Do It? Software Education Associates Ltd.

[4] Technology. Retrieved from http://www.bbc.com/news/technology - 21280943.

[5] Swapnil, C. H, \& Mahip, B. M. (February 2013). New computing paradigm: Software testing in cloud, issues, challenges and need of cloud testing in today's world. International Journal of Emerging Research in Management and Technology. 
[6] Chan, W. K., Lijun, M., \& Zhenyu, Z. (2009). Modeling and testing of cloud applications.

[7] Rahul, M., \& Prince, J. (2013). Testing techniques and its challenges in a cloud computing environment. The SIJ Transactions on Computer Science Engineering and Its Applications (CSEA).

[8] Sosinsky, B. (2011). Cloud Computing Bible. Indianapolis, Indiana.

[9] Developerworks. Retrieved from http://www.ibm.com/developerworks/rational/newto/

[10] Sharma, A. (2012). Data management and deployment of cloud applications in financial institutions and its adoption challenges. International Journal of Scientific \& Technology Research,.

[11] Developerworks.

Retrieved

from http://betanews.com/2013/11/04/comparing-cloud-vs-on-premise-six-hidden-costs-people-always-f orget-about/

[12] Meskerem, A., \& Abrehet, M. O. (December 2013). Cloud computing security framework for banking industry. HiLCoE Journal of Computer Science and Technology, 2(1).

[13] Meskerem, A., \& brehet, M. O. (20130. Cloud computing security framework for banking industry. HiLCoE Journal of Computer Science and Technology.

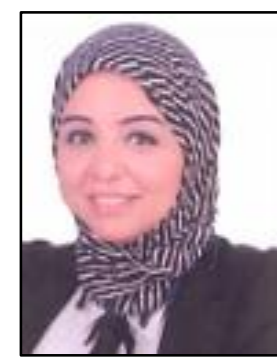

Aya El Nagdy graduated from Faculty of Computer Science and Information Technology in 2009. Studied Quality control and assurance diploma at information technology institute 2010, she worked as testing engineer for 2 years for testing banking applications, then she worked as a test analyst in National Bank of Abu Dhabi for Migration project of core banking system. She is now working as an infrastructure specialist at IBM. She has been involved in testing multiple banking systems. She is currently engaged in research involving Testing framework for cloud based applications for banking applications

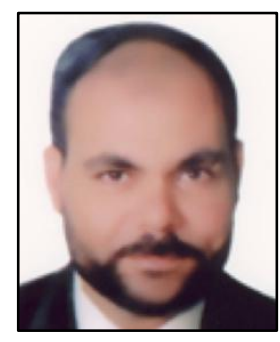

Mostafa Abd El Azim was born on 17 July 1957 at el shrkia governorate. He was graduated from Military Technical College from computer engineering dept. 1980 at Cairo BS.C in computer engineering, Egypt with degree distinct excellence, and award MSc from faculty of engineering, Cairo University 1984, and awarded Ph.D. from Cranfield University 1992 in United Kingdom in the field of computer sciences. He promoted to senior professor 2004 in computer sciences \engineering in the field of software engineering. His current research focus on Internet of Things (IOT), Software engineering, Multimedia security, cloud computing, Mobile agent applications, Bioinformatics and Big data.

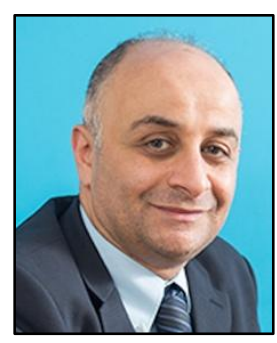

Ashraf M. AbdelRaouf achieved his PhD in 2012 from the School of Computer Science at the University of Nottingham, Nottingham, UK. He was graduated from the Faculty of Engineering 1988. He studied a computer science diploma in 1990 at the American University in Cairo (AUC). He worked in the software and IT industries. Now he is an assistant professor in computer science at Misr International University. In the IT business industry, he was working as a chief operating officer (COO) at Cloudypedia, Egypt. Cloudypedia is a premium Google business partner. His research interest is pattern recognition specifically in character recognition, natural language processing, image processing, Bioinformatics, Arabic linguistics and morphology. Other research interests include Data Structures and algorithms, computer graphics, cloud computing and big data. 